\title{
CONTRIBUIÇÕES DA PSICOLOGIA A UM PROJETO DE EDUCAÇÃO AMBIENTAL
}

Anne Carolynne Bogo

Centro de Psicologia Comportamental

Felipe Boldo Martins

Universidade Estadual de Londrina

Carolina Laurenti

Universidade Estadual de Maringá; Universidade Estadual de Londrina
Recebido em: 25/07/2019

$1^{\text {a }}$ revisão em: 10/10/2019

Aceito em: 06/04/2020

\section{RESUMO}

O projeto de extensão "Educação ecológica, desenvolvimento regional e cidadania global: a conservação de riachos urbanos da região metropolitana de Maringá" é um trabalho interdisciplinar, cujo objetivo era sensibilizar a população e os futuros cidadãos sobre a necessidade da conservação dos riachos urbanos e fundos de vale. A execução do projeto se deu por meio de mostras científicas em escolas da região metropolitana de Maringá e contou com a participação de diversas áreas do conhecimento, como biologia, psicologia, geografia e artes cênicas. A psicologia analisou a efetividade das atividades realizadas nas escolas e indicou que a proposta de educação ambiental estava mais voltada para a dimensão comportamental do "dizer" que do "fazer". A análise psicológica propôs, então, algumas mudanças no projeto de modo que os alunos não só falassem ("dizer") sobre a preservação do meio ambiente, mas que também emitissem comportamentos ("fazer") tidos como pró-ambientais.

Palavras-chave: psicologia ambiental; educação ambiental; análise do comportamento; interdisciplinaridade. 


\title{
CONTRIBUTIONS OF PSYCHOLOGY TO AN ENVIRONMENTAL EDUCATION PROJECT
}

\begin{abstract}
The extension project "Ecological education, regional development, and global citizenship: preserving urban streams in the metropolitan region of Maringá" is an interdisciplinary project which aims to raise both current and future citizen's awareness towards the preservation of urban streams and valley bottoms. The implementation of the project consisted of scientific exhibitions at schools in the metropolitan region of Maringá and shared participation with various areas of expertise, such as biology, psychology, geography, and performing arts. Psychology then analyzed the effectiveness of the activities carried out at the schools and indicated that the proposal for environmental education was more focused on the behavioral dimension of "saying" than "doing". This psychological analysis suggested some alterations to the project so that students not only said about environmental preservation, but also emitted behaviors considered proenvironmental.
\end{abstract}

Keywords: environmental psychology; environmental education; behavior analysis; interdisciplinarity.

\section{CONTRIBUCIONES DE LA PSICOLOGÍA A UN PROYECTO DE EDUCACIÓN AMBIENTAL}

\section{RESUMEN}

El proyecto de extensión "Educación ecológica, desarrollo regional y ciudadanía global: la conservación de riachuelos urbanos de la región metropolitana de Maringá" es un trabajo interdisciplinar, que tiene por objetivo sensibilizar a la población y los futuros ciudadanos sobre la necesidad de conservar los riachuelos urbanos y fondos de valle. La ejecución del proyecto ocurrió por medio de exposiciones científicas en escuelas de la región metropolitana de Maringá, con participación de diversas áreas de conocimiento, como biología, psicología, geografía y artes escénicas. La psicología analizó la efectividad de las actividades realizadas en las escuelas y indicó que la propuesta de educación ambiental estaba más centrada en la dimensión conductual de "decir" que "hacer". El análisis psicológico luego propuso algunos cambios en el proyecto para que los estudiantes no solo hablaran ("decir") sobre la preservación del medio ambiente, sino también comportamientos emitidos ("hacer") considerados pro-ambientales.

Palabras clave: psicología ambiental; educación ambiental; análisis de la conducta; interdisciplinariedad. 


\section{INTRODUÇÃO}

Quando se pretende entender e intervir na realidade humana, destaca-se a importância da inter-relação com outras áreas do conhecimento para que esse entendimento e intervenção não sejam fragmentados e unilaterais, o que poderia incorrer em reducionismos (Ramos-Cerqueira, 1994). Integrar e articular estudos e práticas de vários campos do saber, para que haja a compreensão da complexidade do fenômeno a ser estudado, é o que se denomina interdisciplinaridade (Pombo, 2005). Considerando as excessivas especializações que assolam a produção na ciência, a interdisciplinaridade permanece como um objetivo a ser alcançado por diferentes disciplinas científicas (Pombo, 2005; Ramos-Cerqueira, 1994; Romice, 2005). Isso tem sido reconhecido inclusive por agências de fomento à pesquisa e extensão, que têm demandado e valorizado propostas de caráter interdisciplinar (p. ex., Agência FAPESP, 2019).

Um exemplo de trabalho interdisciplinar que será alvo de discussão neste texto é o projeto de extensão "Educação ecológica, desenvolvimento regional e cidadania global: a conservação de riachos urbanos da região metropolitana de Maringá" do Núcleo de Pesquisas em Limnologia, Ictiologia e Aquicultura (Nupélia) da Universidade Estadual de Maringá. Inserido no programa Universidades Sem Fronteiras (USF), o projeto criou oportunidade para a participação de profissionais de diversas áreas do conhecimento, como biologia, geografia, artes cênicas e psicologia. O objetivo era "sensibilizar a população e especialmente os futuros cidadãos (estudantes do ensino fundamental) sobre a necessidade e urgência da conservação dos riachos urbanos e fundos de vale, visando uma melhor qualidade de vida e saúde integral" (Programa Universidade Sem Fronteiras, 2018). Uma vez que a poluição de fundos de vale e de rios pode gerar problemas como a destruição de habitats e disseminação de epidemias (dengue, febre amarela, zika e chikungunya) e de espécies indesejáveis (escorpiões, aranhas, moscas), parece ser necessária a mudança de comportamentos da população em geral, visto os impactos negativos no ecossistema local. Para isso, a identificação do problema e as intervenções foram construídas com base em um caráter interdisciplinar, com o propósito de angariar e articular contribuições de diversas áreas do conhecimento.

A inserção da psicologia no contexto desse projeto se deu quando ainda vigorava um projeto anterior intitulado "Se todos campearem (Capacitação e Ação Motivada à Preservação, Educação Ambiental e Recuperação de Ecossistemas Aquáticos), a conservação acontece", que tinha por objetivo "sensibilizar o maior número de pessoas sobre a conservação dos riachos e o problema do lixo nas cidades" (Universidade Estadual de Maringá, 2017). A equipe solicitou, então, que a psicologia fizesse uma apreciação das atividades do projeto "Se todos campearem...", que consistiam na realização de mostras científicas sobre o ecossistema dos rios em escolas públicas. A análise psicológica dessas mostras daria subsídios para eventuais alterações em atividades que seriam 
implementadas no projeto "Educação ecológica, desenvolvimento regional e cidadania global".

O primeiro desafio foi elucidar as possíveis contribuições da psicologia no âmbito do projeto. Isso porque tal área de conhecimento é plural (Abib, 2009) e, portanto, há diferentes teorias que fazem parte do campo psicológico. A teoria que orientou a atuação da psicologia foi a Análise do Comportamento. Para essa perspectiva psicológica, o objeto de estudo é o comportamento, entendido como a relação de um organismo qualquer (humano ou não humano) com seu ambiente (social e não-social) (Skinner, 1974). Essa concepção contextual de comportamento dá suporte para entender as ações humanas, tanto públicas quanto encobertas, ao situá-las no contexto imediato e histórico. Esse último é bastante complexo, uma vez que inclui a história de vida do indivíduo, da cultura da qual faz parte, e a história evolutiva da espécie (Abib, 2007; Skinner, 1974).

A psicologia analítico-comportamental possui estudos e intervenções em educação ambiental nos quais foram demonstrados, por exemplo, como aumentar a probabilidade de ocorrência de comportamentos sustentáveis em um dado contexto (e.g., Abreu, 1990; Dal Ben \& Melo, 2016; Frazer \& Leslie, 2014; Keller, 1991; Steg \& Vlek, 2009). Entendendo o papel da psicologia na orientação teórica da Análise do Comportamento, uma apreciação psicológica das atividades de educação ambiental envolvia, então, um exame dos objetivos e das atividades do projeto de educação ambiental em termos de comportamento.

Dado esse panorama, o objetivo deste relato é apresentar algumas contribuições da psicologia analítico-comportamental para o delineamento de uma proposta de educação ambiental no âmbito do projeto "Educação ecológica, desenvolvimento regional e cidadania global". Isso será feito por meio da descrição de uma análise psicológica das atividades desenvolvidas em um projeto anterior a esse ("Se todos campearem..."), que pautou as sugestões de aprimoramento das atividades a serem implementadas no projeto. Para tanto, este relato de experiência se guiará pelo seguinte percurso: apresentação do projeto "Se todos campearem..."; análise psicológica dos objetivos delimitados e das atividades executadas; descrição das propostas da psicologia pautadas na análise realizada; e a implementação das propostas no projeto "Educação ecológica...".

\section{MÉTODO}

O foco da análise psicológica seria uma das mostras científicas realizada em uma escola municipal, com vistas a identificar se os objetivos propostos pelo projeto "Se todos campearem..." estavam sendo atingidos. Seriam verificados quais comportamentos do público-alvo da mostra (crianças do ensino fundamental, com faixa etária de 9 anos) estavam sendo priorizados pelas atividades da mostra. Para realizar essa investigação, foram adotados os seguintes procedimentos metodológicos: 


\section{OBSERVAÇÃO NATURALÍSTICA ORIENTADA POR UM DIÁRIO DE CAMPO}

Foi realizada uma observação naturalística, que consiste em observações em um ambiente natural específico com o objetivo de compreender a relação de um indivíduo ou grupo com determinado ambiente. Para isso, pode-se fazer uso de técnicas para a coleta de dados (Cozby, 2003). A técnica utilizada foi um diário de campo, e o ambiente natural observado foi uma mostra científica do projeto "Se todos campearem..." realizada em uma escola municipal da cidade de Maringá. O objetivo da observação era identificar quais comportamentos do público-alvo da mostra estavam sendo privilegiados pelos integrantes da equipe. Essa identificação serviria de pedra de toque para aferir se os comportamentos almejados pelo objetivo do projeto estavam sendo promovidos. As observações foram orientadas por um roteiro que veio a compor o diário de campo. O roteiro reunia questões como: Qual é o comportamento-alvo que se espera desenvolver com a intervenção na escola? Qual é o comportamento que está sendo estabelecido nas atividades de intervenção? Os comportamentos que foram o alvo da intervenção na escola permitiam alcançar os objetivos delineados na proposta de educação ambiental? Quais medidas são adotadas para avaliar a eficácia da intervenção? Como forma de registro dos dados observados na visita à escola municipal foi construído um diário de campo contendo informações sobre local, data, horário de início e término, e o tipo de atividade, descrição das atividades observadas e as respostas às questões do roteiro.

\section{ANÁLISE DOCUMENTAL}

Foram examinados os documentos que regulamentavam os projetos de extensão "Se todos campearem..." (Universidade Estadual de Maringá, 2017) e "Educação ecológica..." (Projeto Universidade Sem Fronteiras, 2018). A análise documental de cada um dos projetos procurou verificar a relação entre os objetivos propostos, as atividades planejadas para alcançá-los e os modos de avaliar o efeito da intervenção.

\section{DESCRIÇÃO CONTEXTUAL DO COMPORTAMENTO}

Com base nos dados registrados no diário de campo sobre a mostra científica do projeto "Se todos campearem..." foi possível identificar e descrever algumas variáveis envolvidas no comportamento que estava sendo ensinado aos/às estudantes. Para realizar as análises contextuais, foi utilizado o modelo $A B C$, em que são descritas as inter-relações entre o comportamento (B), o contexto antecedente (A) e as consequências produzidas por essa ação (C).

\section{SISTEMATIZAÇÃO DA PROPOSTA}

A sistematização da proposta a ser implementada no projeto "Educação ecológica..." foi desenvolvida com base na comparação entre as informações obtidas pelo diário de campo e pelas análises contextuais, e os objetivos da 
proposta de educação ambiental delineada nos documentos consultados. Essa comparação permitiu verificar a correspondência entre o comportamento que se pretendia ensinar, tal como descrito nos documentos, e o que estava sendo de fato ensinado por meio das atividades da mostra, para, então, propor adequações que os aproximassem. Os resultados são apresentados a seguir.

\section{RESULTADOS E DISCUSSÃO}

\section{O PROJETO "SE TODOS CAMPEAREM...": ANÁLISE DA RELAÇÃO ENTRE OBJETIVOS E ESTRATÉGIAS}

O projeto "Se todos campearem (Capacitação e Ação Motivada à Preservação, Educação Ambiental e Recuperação de Ecossistemas Aquáticos), a conservação acontece" teve suas atividades desenvolvidas entre fevereiro de 2018 e janeiro de 2019. Nesse período, foram realizadas as atividades como: mutirões para retirada de resíduos sólidos dos riachos do entorno da cidade de Maringá e mutirões para plantio de espécies nativas da Floresta Estacional Semidecidual; coletas de amostras de parâmetros limnológicos e da comunidade biológica dos riachos (fitoplâncton, zooplâncton, peixes, fungos aquáticos, vegetação ripária, macroinvertebrados) em conjunto com outros profissionais e com a comunidade; palestras em ambientes públicos da cidade sobre a importância da responsabilidade ambiental dos cidadãos, e atividades com alunos em escolas da rede municipal de Maringá.

Parte do trabalho da psicologia consistiu em analisar os objetivos do projeto em pauta e como eles poderiam ser ou estariam sendo alcançados por meio das atividades propostas. O objetivo geral do projeto "Se todos campearem..." era: sensibilizar o maior número de pessoas sobre a conservação dos riachos e o problema do lixo nas cidades. "Sensibilizar" é o principal verbo que descreve o objetivo desse projeto. O que seria sensibilizar em termos psicológicos? Como "sensibilizar" poderia ser entendido em termos de comportamento? Do ponto de vista psicológico (i.e. comportamental), existem duas diferentes dimensões do comportamento, comumente denominadas "dizer" e "fazer". Nem sempre o relato verbal ("dizer") de uma pessoa tem correspondência com os comportamentos que efetivamente ocorrem na situação descrita pelo relato ("fazer") (Ricci \& Pereira, 2006). Nesse sentido, "sensibilizar" parece ter relação com essas duas dimensões do comportamento. Na dimensão do "dizer", os indivíduos estariam sensibilizados sobre a conservação dos riachos e o problema do lixo nas cidades, se, em situações com presença de lixo, houvesse a ocorrência do comportamento de falar sobre as formas corretas de descarte, e sobre as consequências para o meio ambiente e para a sociedade do descarte (in)adequado de lixo. Considerando a dimensão do "fazer", as pessoas estariam sensibilizadas para a questão ambiental se, em situações com presença de lixo, houvesse a ocorrência dos comportamentos de coletar o lixo e de levá-lo ao local de descarte adequado, produzindo as consequências benéficas para o meio ambiente e a sociedade. Estudos da área sobre a correspondência entre falar e 
fazer, e fazer e falar indicam que essa relação não é obrigatória. Isso significa que os indivíduos não necessariamente fazem algo por terem falado que fariam, e nem relatam com precisão aquilo que fizeram (Brino \& De Rose, 2005). Logo, ensinar uma pessoa a falar sobre a conservação do meio ambiente não significa que ela, de fato, emitirá comportamentos tidos como pró-ambientais.

\section{AS ATIVIDADES DO PROJETO}

Uma parte da mostra observada na escola foi realizada em uma sala de multiuso e outra parte no pátio. A turma atendida era formada por cerca de 30 alunos, e foi subdividida em dois grupos de 15 crianças cada para a participação nas atividades da mostra, cuja descrição consta na Figura 1.
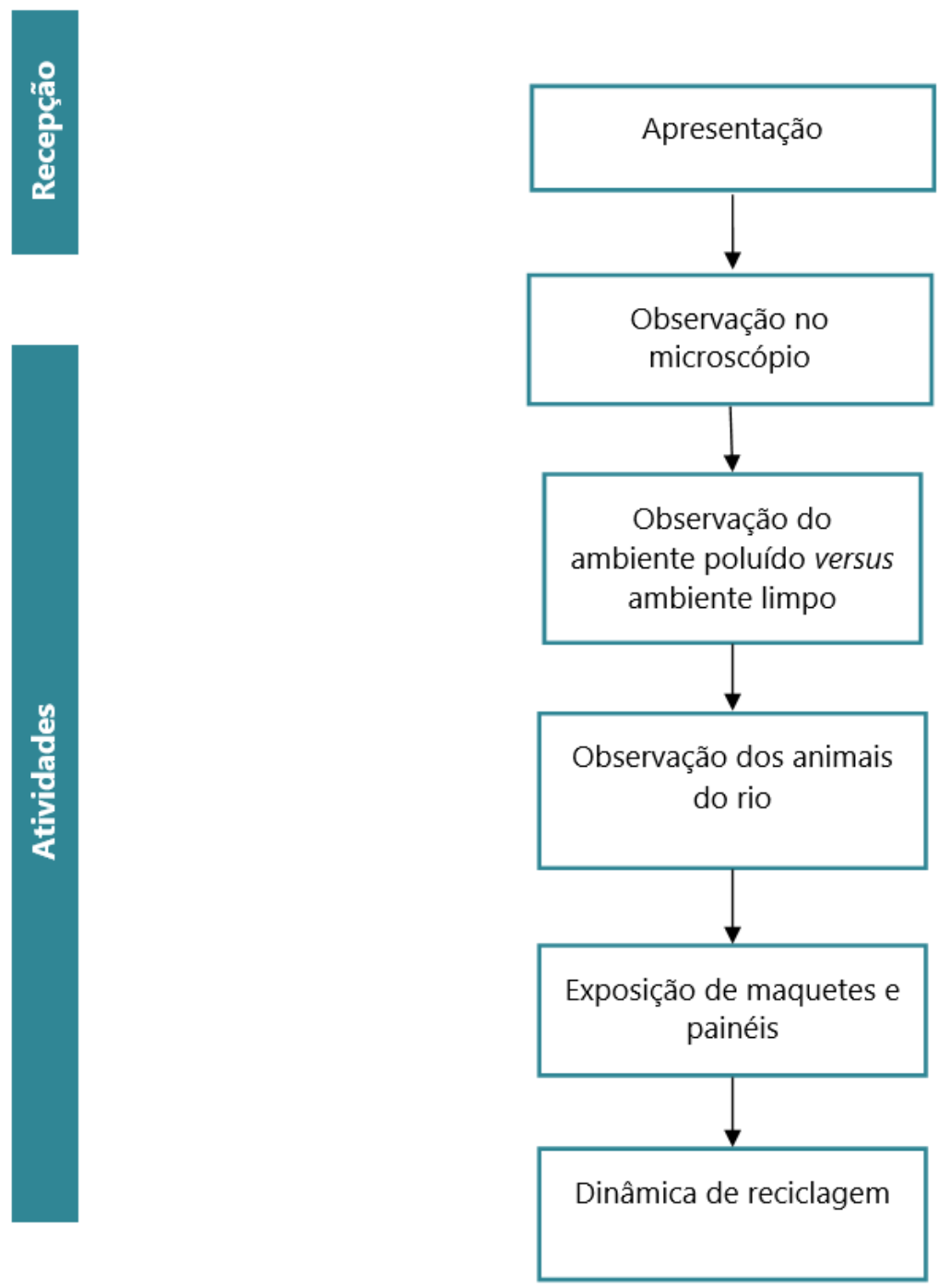

\section{Figura 1.}

Fluxograma das atividades realizadas nas escolas no projeto "Se todos campearem". Representação da sequência das atividades realizadas durante o projeto. 
Examinando o principal objetivo do projeto (sensibilizar os indivíduos quanto às consequências do descarte inadequado de lixo), à luz da discussão apresentada a respeito das dimensões da sensibilização, surge, então, a pergunta: quais dimensões dessa sensibilização (dizer/fazer) as atividades planejadas no projeto presumivelmente atingem? Se há a pretensão de uma correspondência entre o dizer e o fazer no tocante aos comportamentos pró-ambientais, estariam as atividades planejadas contemplando essas dimensões envolvidas no sensibilizar?

A Tabela 1 reúne as atividades observadas na exposição da mostra, conforme a perspectiva psicológica analítico-comportamental. De acordo com essa teoria, a análise contextual de um comportamento precisa considerar a inter-relação entre a ação, o contexto antecedente no qual ela ocorre e as consequências produzidas. Além disso, a Tabela 1 também destaca a dimensão comportamental (dizer ou fazer) que foi privilegiada em cada atividade.

Tabela 1.

Análise contextual das atividades observadas na mostra

\begin{tabular}{l|c|c|c|c} 
Atividades & $\begin{array}{c}\text { Situação } \\
\text { antecedente }\end{array}$ & Ação & Consequência & $\begin{array}{c}\text { Ênfase } \\
\text { dizer/fazer }\end{array}$
\end{tabular}

(1) Apresentação

(2) Observação no microscópio

(3) Observação do ambiente poluído versus ambiente limpo

(4) Observação dos animais do rio

(5) Exposição de maquetes e painéis

$$
\begin{aligned}
& \text { Questionamento Responder elogios às } \\
& \text { sobre o às respostas } \\
& \text { conhecimento perguntas; sobre o } \\
& \text { prévio a comentar; manejo } \\
& \text { respeito do lixo observar adequado e } \\
& \text { e de rios; os correções das } \\
& \text { apresentação de materiais; respostas } \\
& \text { materiais; perguntar acerca do } \\
& \text { perguntas sobre sobre os manejo } \\
& \text { os materiais materiais inadequado } \\
& \text { do lixo }
\end{aligned}
$$

Dizer

(6) Dinâmica da reciclagem

$\begin{array}{cc}\text { Objetos para } & \text { Levar o } \\ \text { descarte e } & \text { objeto até } \\ \text { caixas com as } & \text { à caixa } \\ \text { cores indicativas } & \text { adequada } \\ \text { de cada material } & \text { para seu } \\ \text { de descarte } & \text { descarte }\end{array}$

Remoção do lixo (ambiente limpo), elogios e atenção social
Fazer

No tocante à (1) apresentação, os antecedentes são os questionamentos feitos pela equipe às crianças sobre o conhecimento prévio a respeito do lixo e dos rios. Esse antecedente cria condições para ações de responder às perguntas e fazer comentários. Com isso, a ação das crianças de falar sobre o lixo e sobre o rio 
produziu algumas consequências, como elogios, por parte da equipe do projeto, às respostas corretas e explicações sobre o efeito causado na natureza quando o lixo é descartado de forma inadequada. Se uma criança verbalizasse algo como "não pode jogar lixo no rio porque isso torna suja a água que a gente bebe", os coordenadores respondiam: "Isso mesmo! Então como a colega de vocês disse, não podemos jogar lixo no rio, pois a água fica poluída e faz mal para nós, e também para os animais". De acordo com a análise realizada, a ação de falar sobre o que se sabe sobre os rios é seguida por consequências sociais (aprovação verbal, elogios), tendo como foco a dimensão do comportamento.

Sobre a atividade de (2) observação no microscópio, foi possível identificar a situação antecedente pela apresentação dos microscópios, explicações sobre o seu funcionamento, permissão para sua utilização e liberdade para questionamentos e comentários sobre descarte de lixo. Frente a isso, as crianças emitiram ações como: olhar no microscópio, ouvir a explicação, falar sobre o descarte (in)adequado de lixo e seus impactos para o meio ambiente. Como consequência a essas ações, as crianças produziram atenção por parte dos integrantes do projeto, respostas para as suas perguntas, elogios e validação de seus comentários. Se as consequências foram produzidas pelo falar sobre algo, então, a ênfase está na dimensão verbal (dizer) do comportamento.

As atividades de (3) observação de ambiente poluído versus ambiente limpo, (4) observação dos animais do rio e (5) exposição de maquetes e painéis seguiram o mesmo padrão. As situações antecedentes de cada atividade podem ser verificadas pela apresentação de uma nova situação, com objetos, animais, realização de perguntas e explicações. Tudo isso está inter-relacionado com as ações das crianças de falar sobre o manuseio do lixo e suas consequências para a conservação de rios e riachos. Com isso, aquelas ações produziam como consequência atenção social, explicações, elogios etc., cuja ênfase também se encontra no falar e não necessariamente no fazer.

Por outro lado, a atividade da (6) dinâmica da reciclagem parece ter priorizado a dimensão do fazer. A situação antecedente é verificada por algumas caixas com as cores comumente representadas em recipientes de diferenciação de material reciclável (metal, plástico, papel, vidro etc.). A disponibilidade e a disposição desses materiais funcionavam como situação antecedente para a ação de levar o objeto até à caixa adequada para seu descarte, produzindo consequências como ambiente limpo, acertos, elogios e atenção social. A atenção era geralmente produzida tanto pelos(as) coordenadores(as) quanto pelos(as) alunos(as) participantes. Em suma, houve ênfase na dimensão do fazer, pois o que foi diretamente consequenciado nessa atividade foi o comportamento de jogar o lixo de forma adequada.

Em síntese, as atividades de (1) apresentação, (2) observação no microscópio, (3) observação de ambiente natural versus ambiente poluído, (4) observação de animais do rio e (5) exposição de maquete e painéis, são atividades que 
consequenciavam o comportamento de falar sobre rios e riachos, e manuseio de lixo. Diferentemente, entre todas as atividades previstas, apenas a (6) dinâmica da reciclagem parece ter contemplado a dimensão comportamental do fazer. Retomando o objetivo do projeto, sensibilizar as pessoas quanto às consequências do descarte inadequado de lixo, e a análise sobre as duas dimensões de sensibilizar, concluiu-se que a maioria das atividades realizadas na mostra privilegiava a dimensão do dizer, e que atividades voltadas ao fazer poderiam ser ampliadas.

\section{DELINEAMENTO DE PROPOSTAS PARA O PROJETO "EDUCAÇÃO ECOLÓGICA..."}

Após a análise da mostra científica do projeto "Se todos campearem..." foram delineadas algumas propostas de mudança nas atividades que poderiam ser implementadas no projeto "Educação ecológica...". A apresentação dessas propostas ocorreu em uma reunião com toda a equipe envolvida nesse projeto.

\section{PROPOSTA 1: FOCO NA FORMA DO COMPORTAMENTO E APERFEIÇOAMENTO DA DINÂMICA DA RECICLAGEM}

$\mathrm{Na}$ análise do comportamento de manejo de lixo, o que diferencia o manejo adequado do inadequado e que vai diferenciar as consequências produzidas é a forma (topografia) do comportamento, ou seja, como o comportamento é realizado. No projeto "Se todo campearem...", a atividade que tinha foco na forma do comportamento de manejo adequado era a dinâmica da reciclagem. A proposta foi, portanto, investir nos pontos tratados nessa dinâmica: diferenciar o que é lixo do que não é lixo, diferenciar cada tipo de lixo (orgânico e reciclável, e tipos de recicláveis), e descartá-los nos locais adequados.

\section{PROPOSTA 2: ATIVIDADES DE AVALAÇÃO DOS EFEITOS DA INTERVENÇÃO}

Uma atividade que avalie os efeitos da intervenção deve ter relação direta com aquilo que se pretendeu ensinar. A atividade proposta às crianças no projeto "Se todos campearem..." eram desenhos aplicados antes e depois da mostra. As crianças recebiam uma folha que continha uma instrução para que desenhassem, antes da mostra, o que sabiam a respeito dos rios; e depois da mostra, o que aprenderam sobre os rios. Contudo, desenhar "o que foi aprendido" não especifica qual o desempenho esperado: as crianças podem desenhar desde a cadeia alimentar com plânctons e peixes, ou a quantidade excessiva de lixo, e ambos estariam corretos. Retomando a definição de comportamento-alvo da intervenção, a atividade de avaliação também deve ter relação com esse comportamento.

Para a elaboração de atividades que funcionassem como um pré-teste e como um pós-teste foram sugeridas atividades objetivas de assinalar, encontrar o erro, ligar os pontos etc. Essas atividades deveriam estar relacionadas com os assuntos e ambientes discutidos na mostra científica, como identificação do lixo, 
diferenciação do local adequado de descarte e resíduos ou objetos presentes no chão e no rio que não deveriam estar presentes em ambientes sem intervenção humana. O ideal seria que houvesse uma atividade no teste para cada atividade realizada na mostra. Assim seria possível verificar o efeito da mostra em cada tópico que se pretende ensinar.

\section{PROPOSTA 3: PADRONIZAÇÃO DAS ATIVIDADES DA MOSTRA}

Havia um grande número de integrantes envolvidos na organização da mostra científica do projeto "Se todos campearem...". Isso é um ponto positivo para a manutenção das atividades do grupo, mas poderia dificultar uma padronização daquilo que é dito ou feito, interferindo nos efeitos da intervenção. Para tentar superar essas dificuldades foram feitas três sugestões.

A primeira sugestão foi a padronização da sequência e manipulação dos materiais: como pedir para as crianças se sentarem antes de levá-las ao microscópio; cobrir as placas de vidro com os animais e ir descortinando conforme a fala do responsável. A segunda sugestão consistiu na padronização das instruções que os integrantes da equipe dariam às crianças: listar temas e a sequência do que falar em cada sessão da mostra. A padronização das instruções abrange a descrição de termos técnicos na tentativa de usar expressões mais acessíveis à linguagem infantil. Com a padronização da sequência e das instruções em forma de roteiro aumentar-se-ia a probabilidade de que um membro recém inserido no grupo apresentasse desempenho semelhante ao de outro integrante. A terceira sugestão foi definir um checklist para conferência de todos os materiais, equipamentos e procedimentos necessários para a realização da mostra científica. O preenchimento do checklist poderia ser responsabilidade de um integrante de cada grupo, para que fosse verificada a disponibilidade dos materiais e equipamentos usados e se fizesse a conferência deles antes da visita às escolas. Todas essas ações facilitariam alcançar um padrão na execução da intervenção.

\section{PROPOSTA 4: MUTIRÕES COM ESCOLAS}

Um recurso já utilizado pela equipe, o de organizar mutirões em alguns rios e riachos, poderia ser realizado em parceria com as escolas, principalmente aquelas com diferença não significativa entre o pré e o pós-teste. Esta seria uma oportunidade de envolver os alunos e seus familiares em uma atividade prática, de lazer, com objetivos educativos para toda a comunidade.

\section{INCORPORAÇÃO DAS PROPOSTAS NO PROJETO "EDUCAÇÃO ECOLÓGICA..."}

A mostra do projeto "Educação ecológica..." foi realizada em escolas de Maringá e de algumas cidades da região, com alunos do $3^{\circ}$ ano do ensino fundamental. Foram atendidas 9 escolas na cidade de Maringá (8 públicas e 1 particular), 8 em 
Paiçandu, 4 em Sarandi, e 1 em Campo Mourão, totalizando 24 escolas atendidas e 1800 alunos atingidos.

Após a apresentação das propostas à equipe, algumas delas foram incorporadas no decorrer do projeto "Educação ecológica...". Das quatro propostas acima mencionadas, duas foram implementadas na íntegra: a reformulação de atividades de avaliação dos efeitos da intervenção, e o aperfeiçoamento da dinâmica da reciclagem com foco na forma do comportamento. As sugestões de padronização das atividades da mostra e mutirões com as escolas, até o momento de redação deste manuscrito, não haviam sido implementadas.

Para medir os efeitos da intervenção foi proposta a realização de atividades relacionadas com os temas que seriam abordados na mostra. O primeiro passo foi selecionar tais temas. Em conjunto com os demais integrantes foi delimitado o conteúdo a ser avaliado: (1) Caracterização de ambiente poluído: animais típicos de ambiente poluído (menos peixes e mais animais peçonhentos), presença de maior quantidade de lixo; (2) Caracterização de ambiente limpo: animais típicos de ambiente limpo (maior diversidade de animais, peixes e plantas), sem presença de lixo; (3) Diferenciação entre lixo orgânico, reciclável e entulho; (4) O caminho do lixo: separação do lixo orgânico e do reciclável, separação dos tipos de recicláveis, recicláveis vão para as cooperativas.

Após a delimitação dos temas, foram desenvolvidas duas atividades, uma para o pré-teste e outra para o pós-teste. Cada atividade continha 8 questões em que era esperado que a criança relacionasse imagens de rejeitos com palavras (por exemplo, reciclável, não reciclável, entulho), assinalasse animais que podem ser encontrados em maior quantidade em riachos, argumentasse a respeito da preferência de viver próximo a um ambiente limpo ou poluído etc. As atividades eram enviadas às escolas com antecedência. O pré-teste deveria ser aplicado aos alunos antes das atividades da mostra pelo(a) professor(a) da turma; e o pósteste, da mesma forma, após as atividades.

Com base na proposta de aperfeiçoamento da dinâmica da reciclagem com foco na forma do comportamento foi possível desenvolver um novo formato da mostra, que foi pensado em conjunto com um integrante de artes cênicas que também participava do projeto. Ele foi responsável por inserir um caráter lúdico na mostra, para envolver os(as) alunos(as) e torná-la mais interativa. Com essa nova estrutura, que demandava mais tempo que a mostra anterior, não seria mais possível dividir as turmas em dois grupos de 15 crianças cada, de modo que os 30 alunos deveriam participar das atividades da mostra ao mesmo tempo. A equipe da biologia contribuiu com as informações necessárias para o planejamento das atividades, principalmente na descrição do comportamentoalvo que a intervenção pretendia promover: o manejo adequado de resíduos como gerador da conservação dos rios e riachos. A equipe da psicologia assegurava que o aspecto lúdico e as atividades desenvolvidas tinham como 
efeito priorizar a dimensão do fazer, sem desconsiderar o dizer. Assim, as atividades da mostra nas escolas passaram a seguir o modelo da Figura 2:
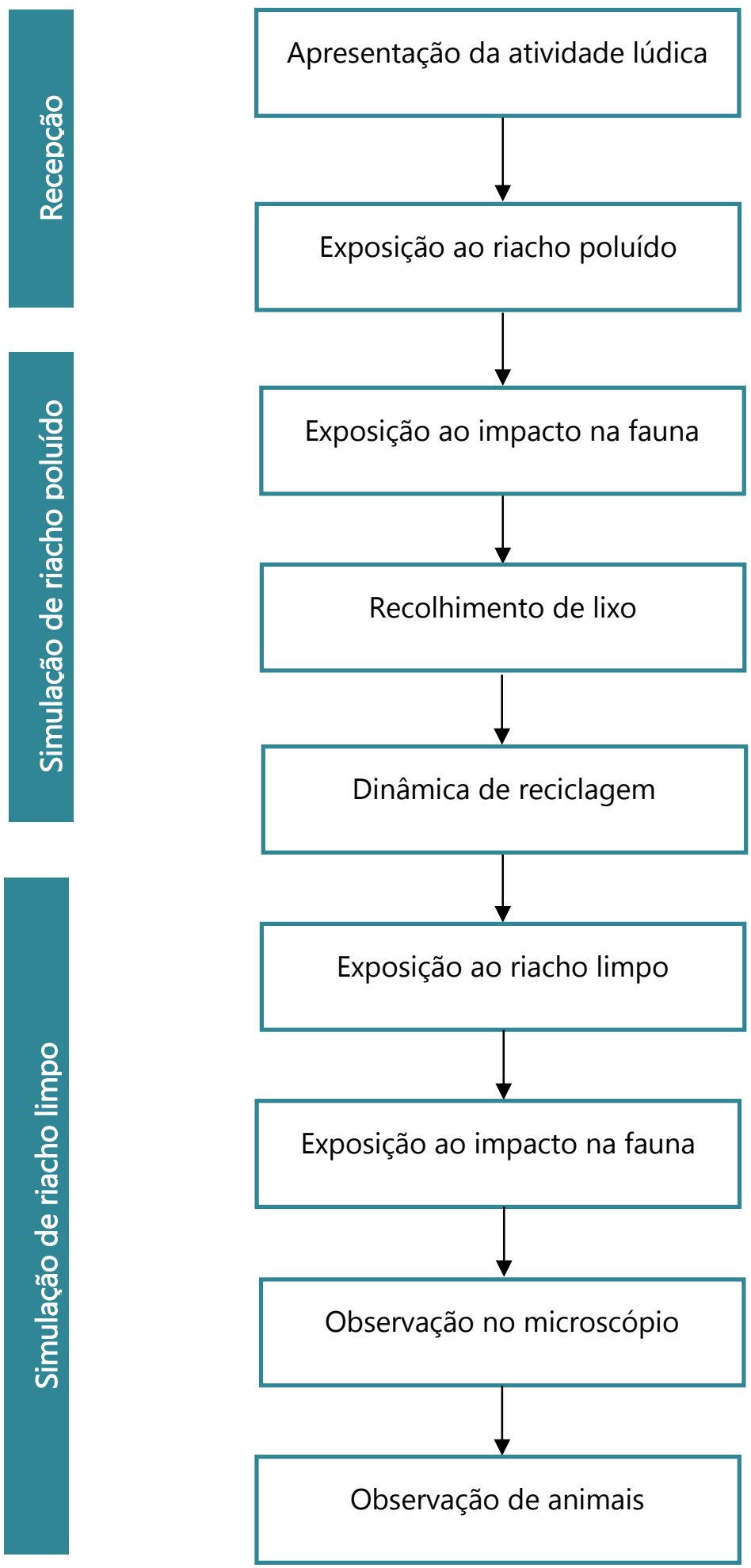

Figura 2.

Fluxograma das atividades realizadas nas escolas no projeto "Educação ecológica". Representação da sequência das atividades realizadas durante o projeto. 
As crianças eram recebidas no pátio pelo integrante das artes cênicas que realizava uma (1) apresentação da atividade lúdica da qual elas participariam: atuariam como "peixes", e "entrariam" no riacho. Nessa apresentação, as crianças eram convidadas a assumir o papel do personagem "peixe", e a "nadar" até o local das demais atividades. Ao entrar no espaço destinado para a realização das atividades, elas eram (2) expostas à representação de um fundo de riacho poluído. Eram instruídas a explorar o local, perceberem o lixo, e (3) a fauna presente (foram utilizadas miniaturas de insetos e animais de acordo com a variedade e a quantidade esperada em um ambiente poluído). Nessa exposição, enfatizou-se a dificuldade de locomoção e alimentação do peixe, que poderia confundir o lixo com algum alimento, evidenciando, ainda, a escassa variedade de insetos e animais presentes. Então, elas eram convidadas a se transformar em agentes do meio ambiente, e a (4) recolher os materiais considerados "lixo" que estavam no fundo do riacho. Importante destacar que galhos e folhas não eram tratados como "lixo" que não deveriam estar nos riachos. Após recolherem os materiais, as crianças eram encaminhadas para a (5) dinâmica da reciclagem. Ali, eram instruídas a fazer o descarte dos materiais recolhidos nos respectivos recipientes.

Após a dinâmica da reciclagem, iniciava-se uma nova fase na mostra: a (6) exposição ao riacho limpo. No riacho limpo, as crianças podiam "mover-se livremente", "respirar melhor", "encontrar alimentos mais adequados". Eram instruídas a (7) observar novamente o impacto na fauna, agora com maior variedade de insetos e animais. Em seguida, elas podiam (8) observar no microscópio organismos que vivem em riachos que estão em boas condições, e depois (9) observar os animais presentes no riacho e em seu entorno.

A nova configuração das atividades da mostra permitiu que as crianças entrassem em contato com as consequências do comportamento do manejo inadequado e do manejo adequado de lixo. Agora, o comportamento de recolher o lixo e descartá-lo em local adequado gera um ambiente mais agradável para elas e para os "peixes". Retomando os objetivos do projeto (sensibilizar a população e especialmente os futuros cidadãos sobre a necessidade e urgência da conservação dos riachos urbanos e fundos de vale), e a análise sobre as dimensões envolvidas no sensibilizar, pode-se concluir que a mostra do projeto "Educação ecológica..." possui mais atividades que selecionam o fazer. Essa nova configuração contempla atividades que ensinam ações pró-ambientais, capazes de mudar o ambiente e a condição dos riachos.

\section{CONSIDERAÇÕES FINAIS}

O trabalho interdisciplinar, não apenas incentivado por agências de fomento à pesquisa e extensão, é essencial para o desenvolvimento humano ao promover a integração de áreas de conhecimento em favor do enfrentamento e superação de problemas contemporâneos. Neste trabalho interdisciplinar a psicologia pode contribuir com o planejamento de atividades mais focadas no estabelecimento 
do comportamento-alvo de manejo adequado de resíduos - uma necessidade também trazida pela biologia. Mais especificamente, uma análise psicológica do principal objetivo dos projetos de educação ambiental (sensibilizar) mostrou que as dimensões comportamentais do dizer e do fazer são importantes e devem ser consideradas ao se planejar uma intervenção. Entendendo que não há garantia de correspondência entre essas duas dimensões, selecionar e modelar o comportamento de dizer algo sobre preservação ambiental não era suficiente para gerar as mudanças que os projetos tinham por objetivo. Se há a necessidade de que o lixo seja manejado de uma maneira cuidadosa e sustentável, é preciso planejar intervenções que considerem também a dimensão do fazer. A expressão "sensibilizar", nesse sentido, ao ser entendida como comportamento, parece estar relacionada à dimensão do fazer, isto é, que, de fato, seja realizado o descarte adequado de resíduos, bem como o cuidado com outros tipos de interferências humanas na natureza.

Quando se realiza um trabalho interdisciplinar a contribuição não é unilateral. A própria compreensão do objeto de estudo da psicologia pode ser ampliada quando a discussão do comportamento foi perpassada pelo conhecimento da biologia da acerca dos riachos urbanos e seu estado de conservação e de toda a vida que neles habita, e de como o comportamento de manusear o lixo afeta diretamente esse ecossistema. Conhecer mais de perto o impacto da ação humana no meio ambiente mostra como a inter-relação entre indivíduo e ambiente é inextricável, tornando urgente encontrar maneiras de transformar esse intercâmbio, de modo que não seja mais destrutivo à vida humana e nãohumana. Além disso, conhecer o potencial das artes cênicas para a idealização e implementação do novo formato da mostra deu relevo à importância do lúdico, das emoções, sentimentos e imaginação, que, articulados com a dimensão racional e operativa do saber científico, podem auxiliar no planejamento de estratégias educacionais pró-ambientais mais efetivas em termos do alcance de seus objetivos. Sobretudo, foi possível aprender que um trabalho interdisciplinar pode propiciar resultados mais amplos e efetivos em propostas de educação ambiental.

\section{REFERÊNCIAS}

Abib, J. A. D. (2009). Epistemologia pluralizada e história da psicologia. Scientize Studia, 7(2), 195208. doi:10.1590/S1678-31662009000200002

Abib, J. A. D. (2007). Comportamento e mundo. In J. A. D. Abib, Comportamento e sensibilidade: Vida, prazer e ética (pp. 16-19). Santo André: Esetec.

Abreu, J. L. C. (1990). Controle dos resíduos sólidos com envolvimento de população de baixa renda. Revista de Saúde Pública, 24(5), 398-406. doi:10.1590/S0034-89101990000500008

Agência FAPESP. (2019). Agências de fomento à pesquisa debatem critérios para o financiamento de projetos. Disponível em: <http://agencia.fapesp.br/agencias-de-fomento-a-pesquisadebatem-criterios-para-o-financiamento-de-projetos/30407/>. Acesso em: 25 de junho de 2019.

Brino, A. L. F., \& De Rose, J. C. (2006). Correspondência entre auto-relatos e desempenhos acadêmicos antecedentes em crianças com história de fracasso escolar. Revista Brasileira de Análise do Comportamento, 2(1), 67-77. doi:10.18542/rebac.v2i1.803 
Cozby, P. C. (2003). Observação do comportamento. In P. C. Cozby, Métodos de pesquisa em ciências do comportamento (pp. 123-140). São Paulo, SP: Atlas.

Dal Ben, R., \& Melo, C. M. (2016). Análise do comportamento e sustentabilidade: Revisão dos artigos publicados no Behavior and social Issues de 2005 a 2016. Revista Brasileira de Análise do Comportamento, 12(2), 86-94. doi:10.18542/rebac.v12i2.4401

Frazer, P., \& Leslie, J. (2014). Feedback and goal-setting interventions to reduce electricity use in the real world. Behavior and Social Issues, 23, 20-34. doi:10.5210/bsi.v23i0.4324

Keller, J. J. (1991). The recycling solution: How I increased recycling on Dilworth Road. Journal of Applied Behavior Analysis, 24, 617-619. doi:10.1901/jaba.1991.24-617

Pombo, O. (2005). Interdisciplinaridade e integração dos saberes. Liinc em Revista, 1(1), 3-15. doi:10.18617/liinc.v1i1.186

Programa Universidade Sem Fronteiras. (2018). Educação ecológica, desenvolvimento regional e cidadania global: A conservação de riachos urbanos da região metropolitana de Maringá. Maringá, PR: Universidade Estadual de Maringá.

Ramos-Cerqueira. (1994). Interdisciplinaridade e psicologia na área da saúde. Temas em Psicologia 2(3), 37-41.

Ricci, L. S. V., \& Pereira, M. E. M. (2006). Uma análise da relação entre o dizer e o fazer do professor. Psicologia da Educação, 23, 27-55.

Romice, O. (2005). Conhecimento, interdisciplinaridade e psicologia ambiental. Psicologia USP, 16(1/2), 167-178.

Skinner, B. F. (1974). About behaviorism. New York, NY: Alfred A. Knopf, Inc.

Steg, L., \& Vlek, C. (2009). Encouraging pro-environmental behaviour: An integrative review and research agenda. Journal of Environmental Psychology, 29, 309-317. doi:10.1016/j.jenvp.2008.10.004

Universidade Estadual de Maringá. (2017). Se todos camPEArem (Capacitação e Ação Motivada à Preservação, Educação Ambiental e Recuperação de Ecossistemas aquáticos), a conservação acontece [Formulário de atividade de extensão]. Maringá, PR.

\section{AGRADECIMENTOS}

Os autores agradecem à Evanilde Benedito pelo convite para participação no projeto "Educação ecológica", e também a Barbara F. Zanco, Beatriz B. Contieri, Lucas Henrique de Oliveira e Matheus M. R. Scoarize pelo trabalho em equipe.

\section{CONFLTTOS DE INTERESSES}

Não há conflitos de interesses.

\section{SOBRE OS AUTORES}

Anne Carolynne Bogo é psicóloga pela Universidade Estadual de Maringá, mestre em Análise do Comportamento pela Universidade Estadual de Londrina.

E-mail: annebogo@gmail.com

\section{(1) https://orcid.org/0000-0002-0177-5292}

Felipe Boldo Martins é psicólogo pela Universidade Estadual de Maringá. Atualmente, é mestrando no Programa de Pós-Graduação em Análise do Comportamento da Universidade Estadual de Londrina.

E-mail: boldomartins17@gmail.com

https://orcid.org/0000-0002-5145-979X

Carolina Laurenti é psicóloga pela Universidade Estadual de Londrina, mestre e doutora em Filosofia pela Universidade Federal de São Carlos. Atualmente é professora adjunta no Departamento de Psicologia da Universidade Estadual de Maringá e está credenciada no Programa de Pós-Graduação em Análise do Comportamento da Universidade Estadual de Londrina.

E-mail: claurenti@uem.br

(1) https://orcid.org/0000-0002-5247-9610 